\title{
Different Approaches between First and Second Mass Digitisation Project for the Herbarium (BR) at Meise Botanic Garden
}

Sofie De Smedt ${ }^{\ddagger}$, Ann Bogaerts ${ }^{\ddagger}$, Henry Engledow ${ }^{\ddagger}$, Quentin Groom ${ }^{\ddagger}$

‡ Meise Botanic Garden, Meise, Belgium

Corresponding author: Sofie De Smedt (sofie.desmedt@plantentuinmeise.be)

Received: 13 Jun 2019 | Published: 19 Jun 2019

Citation: De Smedt S, Bogaerts A, Engledow H, Groom Q (2019) Different Approaches between First and Second

Mass Digitisation Project for the Herbarium (BR) at Meise Botanic Garden. Biodiversity Information Science and

Standards 3: e37259. https://doi.org/10.3897/biss.3.37259

\section{Abstract}

The Herbarium of Meise Botanic Garden is in the top 15 herbaria worldwide. The collection comprises some four million specimens, which are important for scientific research.

Digitisation of specimens includes imaging, transcription of label information, linking data and making the results publicly accessible online. In addition to facilitating researchers' access to specimens, digitisation also brings new possibilities for analysis and discovery of new data, such as the vast amount of information on handwritten labels.

In the DOE! project (Digitale Ontsluiting Erfgoedcollecties), funded by the Flemish Government, 1.2 million herbarium sheets from the African and Belgian collections were digitised. We have received additional funding to digitise a further 1.4 million specimens for the remaining vascular plants and macro-algae collections, by October 2021. These include the historic collections of Von Martius and Van Heurck.

Carl Friedrich Philipp von Martius (1794-1868) was a pioneering explorer whose expeditions led to the discovery of many species. He amassed over 300,000 specimens, some of which were used to compile the first Flora of Brazil. 
Henri Van Heurck (1838-1909) also gathered herbarium specimens from all over the world, including a specimen originally from the collection of Linnaeus.

Despite this being our second mass digitisation project, there are significant differences in our approach. This is partly due to lessons learned from the first project and partly to the nature of the collections themselves. The differences in the tendering process, specimen preparation, workflow and data capture will be explained.

Making these specimens openly available online through www.botanicalcollections.be is valuable to scientific research as well as valorising of our collections. Currently, the site attracts 7000 users a year, which adds up to 15,000 sessions a year and the average session is more than 8 minutes. This means that people are actively using our website and these numbers can be expected to grow as we add more specimens and functionality.

\section{Keywords}

herbarium, mass digitisation, data capture, historical collections

\section{Presenting author}

Sofie De Smedt

\section{Presented at}

Biodiversity_Next 2019 